\title{
EL DESARROLLO \\ DE UNA ESPIRITUALIDAD PASTORAL. APORTES PARA UN PROCESO EDUCATIVO...
}

Autor: Víctor Manuel Fernández. Doctor en Teología, Profesor de Teología Moral y Ecumenismo en la UCA, Director de Estudios del Seminario de Río Cuarto (Argentina) y Vicedecano de la Facultad de Teología de Buenos Aires.

Necesidad de unir espiritualidad con acción pastoral. No es suficiente la competencia pastoral se precisa dinamismo espiritual. El seminario debe iniciar este entrenamiento que ha de seguir la formación permanente. El proceso a seguir: reconocer las llamadas de la vida, oración pastoral, sanar la actualidad, sentido de misterio...

Si se piensa que el objetivo fundamental de los seminarios es formar pastores, entonces parece indispensable establecer una íntima relación entre la formación espiritual y la formación pastoral. Lo mismo vale para la formación permanente, cuyas ofertas espirituales no siempre se orientan a alimentar un ministerio bien vivido.

No se trata sólo de desarrollar con intensidad tanto la dimensión espiritual como la dimensión pastoral, sino de promoverlas en estrechísima conexión. La dificultad reside en encontrar caminos prácticos y efectivos para lograrlo․

1 Sintetizo aquí algunos de los aportes que desarrollaré más ampliamente en un libro de próxima aparición: teología espiritual encarnada. Profundidad espiritual en acción, en editorial San Pablo (Buenos Aires). 


\section{Competencia pastoral y profundidad en la acción}

El riesgo de no establecer estas convenientes relaciones está en que no se favorezca la unidad de vida de la persona. La espiritualidad irá por una parte y la actividad pastoral por otra. En tal caso, la preparación pastoral podrá ser muy técnica, lo cual es valioso, pero carecerá de profundidad espiritual, con todos las consecuencias negativas que esto implica.

Es cierto que la competencia pastoral es necesaria para que la persona pueda vivir su ministerio con seguridad y satisfacción. Esa adecuada competencia es indispensable, y es también una respuesta al llamado de Dios. Muchos sufrimientos, temores y complejos provienen de sentirse insatisfecho con el propio ministerio: por no poder orientar a las personas que buscan ayuda, por sentir que uno no puede llegar a la gente en la predicación, etc. Esta angustia fácilmente termina provocando crisis. De hecho, una formación deficitaria en este orden tiene parte de responsabilidad en algunas deserciones tempranas.

Pero la satisfacción y la tranquilidad de quien es capaz de hacer algo bien, sólo se mantiene en un nivel superficial y efímero si le falta dinamismo espiritual. Porque no basta para alimentar la dimensión más profunda de la persona, que queda muy endeble ante los embates de las diversas etapas de la vida, con sus crisis y desafíos. Tarde o temprano esa actividad dejará de satisfacer a la persona porque se hará rutinaria y no terminará de colmar el vacío interior. Esta satisfacción se buscará, entonces, en unos brazos cálidos, en las ilusiones de Internet, en la supuesta libertad de un nómade sin raíces, etc.

Por otra parte, una espiritualidad sin conexión con la actividad pastoral queda encerrada en una dimensión secreta e íntima de la persona, sin tocar su mundo de relaciones, el dinamismo externo, las tareas que le reclaman y apremian cada día. De este modo, también esa espiritualidad se verá expuesta a desaparecer, porque las personas se dejan absorber más inmediatamente o bien por las exigencias y ocupaciones externas o bien por los estímulos que invitan al consumo, al placer y el entretenimiento.

No hay más salida, entonces, que conectar muy bien la espiritualidad y la actividad pastoral, de tal manera que la actividad pastoral sea profundamente espiritual y la espiritualidad sea esencialmente pastoral. Ambas se alimentan y se sostienen mutuamente. 
Pero es un arte que no se improvisa, que no brota mágicamente cuando llega la ordenación. Los años del seminario son el tiempo adecuado para iniciar este entrenamiento, y la formación permanente debería ocuparse de este aprendizaje de un modo privilegiado.

\section{Sugerencias para desarrollar la profundidad espiritual en la misma actividad}

A continuación ofrezco algunos aportes en orden a encauzar adecuadamente este aprendizaje:

\section{El hábito de reconocer los llamados de la vida}

Es necesario ayudar al seminarista -0 al sacerdote joven- a crear el hábito de ser contemplativo en la acción. Para ello, es importante estimularlo permanentemente a compartir lo que ha encontrado de bueno en la gente y en los servicios pastorales. No es saludable reducir las narraciones sobre la tarea pastoral a las anécdotas llamativas, los logros personales y las actividades realizadas. Hay que procurar que se comenten también las interpelaciones recibidas en la actividad, los 1lamados de Dios que se perciben en la acción misma.

Esto puede hacerse tanto en la dirección espiritual como en las reuniones comunitarias, en la revisión del proyecto personal, etc.

Esta costumbre de interpelar al seminarista para que reconozca el mensaje de las personas y del mundo, puede ayudar a que desarrolle poco a poco una disponibilidad y atención amable vivida en las actividades y en el encuentro con la gente. Se trata de un ejercicio de la dimensión receptiva de la vida teologal, que es una de las dos columnas de una buena experiencia pastoral.

Esto implica una liberación del egocentrismo ("Hice tal cosa", "me felicitaron por esto", "una persona me agradeció mucho", "pasé un fin de semana muy interesante", "yo tuve una actividad muy intensa"). Pero también requiere el desarrollo de una capacidad de dejarse enseñar por la vida de los demás y sus inquietudes (cuando se trata de valores que podemos reconocer en los demás), y el hábito de recoger los desafíos externos escuchando cómo Dios habla a través de las per- 
sonas y acontecimientos (también cuando la actividad o las relaciones humanas son conflictivas o insatisfactorias).

Porque en la misma actividad el pastor intenta vivir un constante, sereno y sincero discernimiento de sus actitudes, motivaciones y sentimientos. Porque Dios habla y ofrece su amor también en medio de la tarea a la cual él mismo nos envía. Hay "una llamada que Dios hace oír en una situación histórica determinada. En ella y por medio de ella Dios habla al creyente" (PDV 10). Hay cosas que él dice "en una determinada circunstancia" (EN 43), y que requieren una "sensibilidad espiritual" (ibid) vivida en la misma actividad mundana. El Espíritu otorga permanentemente luces e impulsos que hay que acoger con docilidad en medio del trajín y el vértigo de la acción; la presencia de Cristo resucitado es tan real en medio de la misión que cumplimos como en los momentos de silencio y quietud.

Por otra parte, si Dios nos hace 1legar sus mociones, llamados, impulsos y signos de amor en medio de la existencia mundana, nuestra respuesta debería darse también en medio de esa misma existencia mundana, en la actividad y en el encuentro con los demás.

\section{El hábito de una oración pastoral}

Los estilos y modos de oración que suelen fomentarse en los seminarios serían muy útiles si, terminada la formación, el seminarista se fuera a vivir a un monasterio o a una comunidad contemplativa; pero no suelen ser tan adecuados para la vida en el mundo, con una actividad pastoral intensa.

Evidentemente, esta es la razón principal por la cual los buenos hábitos de oración adquiridos en el seminario suelen perderse al poco tiempo del egreso. Son hábitos muy buenos, pero no adecuados para la misión apostólica que Dios confía.

Por lo tanto, una de las claves para la armonía entre espiritualidad y pastoral está en ayudar a crear un estilo y unos modos de oración que puedan mantenerse con gusto y facilidad en la vida parroquial futura. Tendrá que ser necesariamente una oración en íntima conexión con la actividad pastoral, con sus exigencias, desafíos, gozos y preocupaciones. Esto implicará, ciertamente, llevar a la oración la actividad vivida. Veamos algunos ejemplos de este estilo de oración pastoral: 
Su forma más propia es la intercesión sincera, la necesidad de entregar en la presencia de Dios a las personas que uno atiende, con sus dificultades y progresos.

Otra forma es el hábito de descargarse en la presencia de Dios, conversando con él las resonancias que han producido en el corazón las dificultades, fracasos y exigencias de la tarea.

Otra manera es buscar, en la presencia de Dios y en su Palabra, las motivaciones que puedan brindarle más sentido, luz y entusiasmo a las actividades concretas.

También debe ejercitarse en positivo, gozándose en la presencia de Dios al recordar y ofrecer los momentos agradables, agradeciendo las cosas buenas y felices de los demás, contemplando con agrado la presencia y la acción del Espíritu en nuestra tarea, en el Pueblo de Dios, en la vida del mundo, en la cultura, etc.

\section{El hábito de elaborar profundas convicciones que favorezcan la acción}

La dirección espiritual, y también la formación académica y otras instancias formativas, deberían ofrecer toda una riqueza de motivaciones teológicas que le den sentido y gusto a la acción evangelizadora y a las diversas tareas. Por ejemplo, la teología de los Sacramentos tendría que brindar las razones que hagan profundamente deseable dedicarse a administrar esos sacramentos. La teología de la Creación debería invitar a gozarse en el encuentro con el mundo, reconociendo la variedad de las creaturas y de la vida del mundo como un reflejo de la inagotable riqueza de Dios. Esto, bien planteado, motiva a meterse en el mundo con la actividad evangelizadora, a dialogar con la cultura, a encontrarse con el otro, en lugar de escapar buscando refugios pseudo espirituales. Igualmente, la teología moral ofrece argumentos sólidos para mostrar el primado que tiene la caridad con el prójimo -y consiguientemente el ejercicio de la caridad pastoral en el apostolado- por encima del desarrollo de cualquier otra virtud.

Podríamos encontrar innumerables ejemplos más en las distintas disciplinas teológicas.

La frecuente dicotomía entre la teología y la actividad pastoral, en lugar de favorecer a la actividad pastoral, la empobrece tremendamen- 
te. Pero también tiene su culpa la misma enseñanza teológica, cuando no es planteada de un modo completo, cuando no procura mostrar las resonancias y consecuencias espirituales y pastorales de los contenidos.

\section{Sanar la actividad}

En esta línea, la teología moral, la espiritualidad y la psicología tienen mucho para ofrecer de motivaciones y recursos que ayuden a superar las inclinaciones que enferman a la actividad. Es necesario ayudar al seminarista a controlar sus ansiedades, sus obsesiones, su impaciencia; a reconocer y superar los mecanismos del idealismo, la comodidad, los controles excesivos, etc. Se trata de puntos débiles directamente relacionados con la actividad, que tarde o temprano la vuelven enfermiza, complicada, insatisfactoria. El desarrollo de estas patologías de la actividad tiene que ver con inclinaciones psicológicas, pero también con concepciones erradas sobre la evangelización, el ministerio o la vida cristiana, y con escasas o parciales motivaciones espirituales.

En el diálogo con el seminarista sobre su modo de vivir la actividad, es clave reconocer cuáles son las patologías de la actividad que comienzan a presentarse en su tarea pastoral, para revisar con él las motivaciones reales y profundas de su actividad y así poder modificarlas a tiempo. La transformación de esas motivaciones y el adecuado dominio de estas perturbaciones de la actividad, deberá constatarse luego en la actividad misma.

Posiblemente, en algunos casos, se requiera la ayuda de una buena terapia. La dificultad que yo advierto en ello, es que frecuentemente los formadores procuran orientar la terapia sólo a la resolución de dificultades comunitarias del seminario o de perturbaciones sexuales, y pocas veces a sanar un modo enfermizo de vivir la actividad pastoral.

\section{Percepción del peso institucional de los valores espirituales apostólicos}

En esta línea, es importante que el seminarista advierta que un sano entusiasmo pastoral (expresión de la caridad pastoral) es un valor espiritual necesario para un candidato al sacerdocio. Para ello, es necesario que él advierta claramente que es uno de los más importantes cri- 
terios de discernimiento que los formadores tienen en cuenta y procuran confirmar, junto con los otros elementos de juicio que suelen predominar: la madurez humana, la aptitud para el celibato, la obediencia, la disciplina o la contracción al estudio. Parece mentira, pero cuando se pregunta a los seminaristas cuáles son los elementos a tener en cuenta para discernir sobre el propio crecimiento, raras veces mencionan el entusiasmo apostólico, aun cuando esperan con ansias el fin de semana para ir a las parroquias. ¿Será éste un indicio de que la formación espiritual se ha vuelto una vez más demasiado volcada a lo íntimo, subjetivo e individual, quizás debido al auge posmoderno de terapias y métodos de curación interior?

Será necesario, entonces, confirmar que en el discurso habitual y espontáneo, los formadores no dejen de destacar que la consagración sacerdotal sólo tiene sentido en orden a la misión, y que, por lo tanto, el fervor apostólico con sus variadas expresiones es un criterio clave de discernimiento.

\section{Dos actitudes espirituales-pastorales complementarias}

Para sostener una actividad pastoral sana y vivida con hondura espiritual, es necesario inculcar y alimentar desde el seminario -y también en la formación permanente- dos convicciones profundas que se complementan entre sí. En primer lugar, para poder sobrellevar los fracasos y desilusiones, es indispensable un marcado "sentido del misterio". Pero al mismo tiempo, para evitar escepticismos y una creciente desgana, hay que invitar a una permanente respuesta al amor de Dios en la cual se incorpore toda la creatividad apostólica de la persona. Veamos:

a) Sentido de misterio

En la actividad pastoral no faltan los fracasos, que pueden llevar a la persona a bajar los brazos, o a debilitar su impulso apostólico a causa del orgullo herido. Es verdad que muchas veces los seminaristas y los sacerdotes más jóvenes desean éxitos pastorales a causa de un narcisismo adolescente que se prolonga. Necesitan demostrar quienes son y ser tenidos en cuenta a través de logros apostólicos destacables. 
Por la misma razón, suelen obsesionarse y destacar sobremanera las tareas en las cuales se sienten más capacitados.

El problema es que normalmente los éxitos no responden al ideal que la persona ha forjado, porque nadie puede dejar contentos a todos. Por lo tanto, esta carencia o debilidad de auténticas motivaciones espirituales puede terminar en un profundo descontento que finalmente lleva a reducir al mínimo las actividades pastorales.

Otras veces la persona tiene un deseo sincero y no narcisista de cambiar el mundo, de hacer el bien, de aportarle algo a la vida; pero al descubrir los escasos resultados visibles que se logran a costa de mucho esfuerzo, baja los brazos. Por eso es tan importante educar en el sentido espiritual del misterio. ¿Qué significa esto?

El "sentido del misterio" es saber con certeza que, quien se ofrece a sí mismo a Dios por amor ( $R m 12,1)$, y de ese modo se entrega a la misión que Dios le confía, seguramente será fecundo. Más allá de lo que vean los ojos, será un sarmiento con abundantes frutos (Jn 15, 5); su vida y su actividad no serán estériles.

Jesús decía: "La gloria de mi Padre está en que deis fruto abundante" (Jn 15, 8). Por lo tanto, cuando deseamos ser fecundos estamos respondiendo a su amorosa voluntad. Pero esos frutos se producen de manera misteriosa, esa fecundidad es muchas veces invisible, inaferrable, no puede ser contabilizada. Por eso, el evangelizador puede entregarse intensamente a la misión con la seguridad de que su vida será fecunda, pero sin pretender saber cómo, ni dónde ni cuándo. Dios utilizará también sus aparentes fracasos para realizar misteriosamente alguna obra de su gracia en alguna parte, "por caminos que él conoce" (GS 22) y que no siempre se nos manifiestan.

No se pierde ninguno de nuestros trabajos realizados con amor, no es inútil ninguna de nuestras preocupaciones sinceras por los demás, no es en vano ningún cansancio generoso. Todo eso queda dando vueltas por el mundo como una fuerza de vida que va dando frutos. Bien lo enseñan los orientales con esta imagen: así como, al producir ondas en el mar con el movimiento de nuestras manos, ese movimiento se va propagando por todo el océano, de la misma manera ninguna obra hecha por amor y con amor dejará de modificar al universo. En el orden sobrenatural, esto es lo que llamamos "la comunión de los santos". 
Sin embargo, aunque sepamos en la fe que el dolor del fracaso es también fecundo, eso no quita el dolor. Por eso es necesario encontrar algo más que la fecundidad: una experiencia de amor.

La superación del cansancio escéptico no pasa por eliminar los momentos de aridez o de desaliento, sino por encontrarles un sentido más hondo que el dolor de un yo humillado y desilusionado. La imitación de Jesucristo, que es también una misteriosa asociación a su Misterio, a veces implica experiencias poco gratificantes, pero que no dejan de ser experiencias de amor. Porque, en la Encarnación, Dios se hace solidario con nosotros bajando hasta los fondos de la condición humana. Dios ha experimentado en su Hijo todo lo que implica ser humano: quiso conocer el cansancio, la depresión, la desilusión, la angustia, el temor, la soledad. También el evangelizador participa de estas experiencias humanas, y suele pasar por etapas de aridez, de tedio, de acedia, de cansancio, de desconsuelo, de fracaso. En esas ocasiones, también él baja hasta las profundidades oscuras de la existencia humana y allí puede llegar a experimentar una intensa unión con Jesucristo en su solidaridad con el ser humano, "hasta que duela". De este modo, comulgando en su intimidad con lo más áspero de los sufrimientos humanos, se hace más que nunca hermano de los demás, se vuelve amante hasta el fin.

Es cierto que a veces los momentos de fracaso y debilidad se hacen muy duros para la autoestima, y siempre corremos el riesgo de caer en la depresión, el aislamiento, la dejadez. Por eso es importante aprender a dejarse amar también en el fracaso, aprender poco a poco a dejarse estar en la ternura de los brazos del Padre, dejarse tocar por la gracia permitiéndole a Dios mismo que nos consuele, de manera que no renunciemos al ministerio de derramar consuelo en los demás. El siguiente texto expresa maravillosamente lo que acabamos de decir:

"Dios nos consuela en toda tribulación nuestra para que nosotros podamos consolar a los que están en toda tribulación mediante el consuelo con que nosotros somos consolados por Dios. Pues, así como abundan en nosotros los sufrimientos de Cristo, también por Cristo abunda nuestro consuelo. Si somos atribulados es para consuelo y salvación vuestra. Si somos consolados, lo somos para el consuelo vuestro" (2 Co 1, 4-6). 
b) Respuesta creativa al amor de Dios

Lo que acabamos de decir no implica disminuir el empeño por ser eficientes en la tarea. La preocupación por la calidad y la perfección de la obra externa es también una expresión de la autenticidad del amor, porque indica que no se le quiere regalar a Dios y a los demás algo mediocre o de poco valor. Por el contrario, la dejadez y el desinterés por la perfección de la obra externa y su eficacia, suelen indicar la pobreza de ese amor y en definitiva una débil espiritualidad que no alcanza a tocarlo todo. El estilo de la "nueva evangelización exige la conversión pastoral de la Iglesia, coherente con el Concilio. Lo toca todo y a todos: en la conciencia y en la praxis personal y comunitaria, en las relaciones de igualdad y de autoridad; con estructuras y dinamismos que hagan presente cada vez con más claridad a la Iglesia, Sacramento de Salvación Universal"2.

La espiritualidad evangelizadora no deja afuera nada de cuanto integra la actividad evangelizadora. Todo ha de situarse bajo el impulso del Espíritu de santidad. Por tanto, también el camino responsable planificación pastoral, de preparación, de búsqueda de recursos y técnicas a la luz de la Palabra, forma parte de este proceso de santificación, y ha de vivirse como respuesta al amor de Dios y al impuso del Espíritu.

El Dios creador busca prolongarse en el pastor promoviendo todas sus capacidades, y el Espíritu Santo no quiere instrumentos pasivos. Él nos ama fecundos, desarrollando efectivamente los dones que hemos recibido de su amor desbordante.

Si bien es cierto que el amor que pongamos -los valores que expresemos y desarrollemos en una tarea- ${ }^{3}$ es más importante que los resultados de ese esfuerzo, también es cierto que los resultados son importantes y significativos. El mismo amor reclama nuestra preocupación por cierta eficiencia, porque queremos ofrecerle a Dios algo bello y bien logrado; nos interesa hacer algo verdaderamente útil y eficaz para los demás. Precisamente porque los amamos, no nos resulta indiferente la calidad de lo que podamos ofrecerles. Pero además, si

2 CONFERENCIA GENERAL DEL EPISCOPADO LATINOAMERICANO IV, Nueva evangelización. Promoción humana. Cultura cristiana [SD], Santo Domingo 1992, punto 30.

${ }^{3}$ Verdad acentuada por los defensores de la teoría del "influjo indirecto" del trabajo en el mundo glorioso transfigurado: Cf. C.POZO, Teología del más allá, Madrid 1968,128. 
los resultados del trabajo serán reencontrados en el cielo, y nuestro trabajo prepara "el material del reino de los cielos" (GS 38), entonces no es indiferente que el resultado del trabajo sea bueno y bello o no lo sea. Es verdad que el amor que pongamos es lo que mejor prepara la gloria celestial; pero también es cierto que cuando ese amor busca creativamente la perfección de la obra, y la logra, esa preparación es mayor todavía 4 . Porque el acto de amor se expresa y se encarna de tal manera en esa obra, bella y bien lograda, que es imposible separarlo de ella; aunque también es cierto que ese amor habría sido verdadero y perdurable -de otra manera- aun cuando esa obra externa no se hubiese logrado por factores ajenos a la persona.

Nuestro aprecio por el Reino de los cielos, donde viviremos juntos y felices por toda la eternidad, ofrece entonces una nueva motivación espiritual para trabajar con empeño, responsabilidad y creatividad para mejorar este mundo que amamos. Eso también es una "espiritualidad" encarnada.

Esta convicción es activa y creativa. Implica ofrecerse como instrumento $(\mathrm{Rm} 12,1)$, con todas las propias capacidades, para que todas esas capacidades puedan ser utilizadas por Dios.

Así sucede, por ejemplo, en la predicación: "Esta predicación evangelizadora toma formas muy diversas, que el celo sugerirá cómo renovar constantemente" (EN 43), poniendo en práctica "las exigencias y posibilidades" de la predicación (ibid). La actitud de firme convicción espiritual ante el valor de la predicación implica también valorar "la importancia de los métodos y medios de la evangelización" (EN 40) y entregarse con amor creativo a la preparación de la predicación. Ese amor lleno de convicción y de celo, que busca recursos para llegar al otro, es parte inseparable de la "espiritualidad" del predicador.

Es imperioso entonces superar toda forma de dualismo, como si la búsqueda creativa de recursos eficaces fuera una realidad diferente o separada de la vida según el Espíritu.

La preocupación por el cómo, incluso por la técnica, debería estar incorporada en esta actitud espiritual que es responder creativamente al amor de Dios y amar al prójimo con todas nuestras capacidades.

\footnotetext{
${ }^{4}$ Es el acento de J. L. RUÍZ DE LA PEÑA en la teoría del "influjo directo". Cf. particularmente su obra póstuma: La Pascua de la Creación, Madrid 1996, 188-192.
} 
Si retomamos ahora lo dicho atrás sobre el sentido de misterio, podremos reconocer que la entrega generosa y creativa es necesaria, como parte inseparable de todo amor auténtico. Pero el buen resultado de la obra se buscará por amor a Dios y a los demás, y no por una necesidad egocéntrica de reconocimiento inmediato:

Por eso, el pastor podrá aceptar humildemente que los resultados no sean visibles, sino misteriosos e inaferrables; pero se entregará con la certeza de que toda tarea realizada con amor y empeño creativo de alguna manera produce frutos. Cuando el ser profundo está descentrado en la acción por el amor, y así vitalmente pacificado, entonces su actividad será auténticamente espiritual y propiamente pastoral, porque "el bien es difusivo de sî". Cuando es así, la actividad retroalimenta al ser, lo perfecciona:

"El hombre no llega a ser realmente hombre y no llega a ser plenamente él mismo sino cuando se entrega a una tarea, cuando no hace caso de sí mismo o se olvida de sí mismo al ponerse al servicio de una causa"s.

\section{Establecer puentes entre la actividad y la privacidad}

Teniendo en cuenta las inclinaciones alimentadas por el estilo de vida actual, creo que éste es un aporte educativo fundamental.

Siendo sinceros, hoy no podríamos decir que los curas descuidamos la actividad pastoral por dedicarnos en exceso a la oración privada o al cultivo de formas intimistas de espiritualidad. En realidad, lo que más defendemos son los espacios de privacidad, contrapuestos a la entrega generosa de la actividad apostólica. No terminamos de identificarnos con nuestra misión, y entonces nos sentimos verdaderamente nosotros mismos cuando podemos disponer libremente de nuestro tiempo para lo que nos plazca, pero no siempre cuando estamos ejerciendo el ministerio 6 .

La prioridad del ser por sobre el hacer nos invita a buscar algunas actitudes estables, actitudes de fondo que no se hagan presentes sólo cuando estamos haciendo algo o atendiendo a una persona, e inmediatamente desaparezcan cuando volvemos a nuestra intimidad y accede-

5 V. FRANKL, Teoría y terapia de las neurosis, Barcelona 1997, 17.

${ }^{6}$ A continuación retomo lo que ya desarrollé en mi libro Actividad, espiritualidad y descanso. Vida armoniosa y unidad interior, Madrid 2001, 68-70. 
mos a un momento de libre esparcimiento, sino que se mantengan cuando cesa la actividad porque son verdaderamente personales, libres, espontáneas, porque no son pura apariencia en el cumplimiento meramente funcional de un rol. Así se evita arraigar lo que tan bien describe E. Drewermann, al decir que los sacerdotes, luego de haber compartido algunos momentos con otras personas, "cuando vuelven a casa, a su soledad de siempre, se depositan en su sillón y lanzan un suspiro de alivio"7. Como si allí, en el sillón, recuperaran el sentido real de sus vidas, como si en ese momento volvieran a tener la libertad que perdieron para "adaptarse" esforzadamente a una tarea y a una máscara profesional.

Esta costumbre de separar tanto la actividad de la soledad y el descanso, es sumamente dañina y refleja la carencia una auténtica unidad de vida. Por eso, como decíamos, es conveniente alimentar algunas actitudes básicas estables, que no cesen en la soledad, sino que se expresen de alguna manera también cuando la actividad ha terminado. Habrá que insistir para que el seminarista logre efectivamente desarrollar estas actitudes adquiriendo un determinado hábito. ¿Cómo se logra?

Por ejemplo, evitando el simple gesto externo de alivio y de aparatosa distensión cuando terminamos una actividad pastoral, como si haberla terminado fuera una feliz liberación de un peso insoportable, como si sólo allí retomáramos nuestra verdadera identidad y nuestra opción real.

Más bien conviene, al terminar una actividad, aun cuando haya sido dificultosa y algo agobiante, detenerse brevemente -bastan unos pocos minutos- a darle gracias a Dios por haber podido ser útil, contemplar por un instante la belleza de esa actividad, ofrecerle a Dios las tensiones vividas en ella, hacer una pequeña oración por las personas que hemos atendido. De este modo, dándole un sentido al momento vivido y valorándolo, abrimos el corazón para estar disponibles ante otra actividad semejante que pueda requerirnos, y no estaremos a la defensiva, protegiendo de un modo enfermizo nuestro tiempo de recreación y descanso. Igualmente, nos dispondremos para vivir la actividad de una manera más natural, espontánea, libre, y no tanto como un esfuerzo que contradice nuestras inclinaciones.

Otra posible salida, cuando la actividad no ha sido bien vivida, y nos ha desgastado mucho -porque no estábamos de corazón en ella-es

${ }^{7}$ E. DREWERMANN, Clérigos: psicograma de un ideal, Madrid 1995, 242ss. 
detenerse un instante en oración a imaginar cómo habría sido ese momento si lo hubiéramos vivido con amor, entregándonos enteros, renunciando a nuestros mecanismos de defensa, ofreciéndole al Señor la donación del propio tiempo, poniendo el corazón verdaderamente en las personas y deteniéndonos ante ellas, aflojando las resistencias, etc. Imaginándolo, podemos detenernos a pedir a Dios que transforme el corazón para poder vivir de esa manera las futuras actividades, y con esa oración ya nos disponemos a dar otro sentido a la actividad.

La soledad, cuando la actividad termina, tiene que ser apacible; debería ser un espacio en el cual, poniéndonos frente a Dios, nos reconciliamos con la actividad, con las personas, y, restaurando lo que se ha dañado, logramos despertar una sonrisa agradecida por la vida que llevamos. De otro modo, la soledad se convertirá en el espacio donde rumiamos nuestras insatisfacciones, donde descubrimos angustiados nuestro ser real egocéntrico, y buscamos alguna manera de hallar satisfacciones, sucedáneos y compensaciones para una afectividad no armonizada y para una actividad mal vivida.

\section{Crisis y deserciones}

En el trasfondo de este camino educativo que propongo, subyace la convicción de que mayoritariamente las crisis y deserciones sacerdotales no tienen su origen en un enamoramiento, sino en una actividad apostólica mal vivida. El enamoramiento, cuando existe la posibilidad de encontrar un trabajo aiternativo, es un detonante que ofrece una salida a una situación desagradable y llena de tensiones. Esta situación de incomodidad frente a un ministerio carente de pasión, se ha originado en una ausencia de motivaciones espirituales profundamente arraigadas que otorguen sustento a una actividad tan peculiar como el ministerio sacerdotal. El problema es que esas motivaciones, cuando no se han arraigado en la formación inicial y en los primeros años de sacerdocio, no pueden ahondarse de golpe en el corazón, y menos cuando la situación se ha vuelto insoportable. 